PROJECT REPORT

\title{
Digital Reformatting and Data Rescue with RADD and the PROUD and PRAVDA Kits
}

\author{
Dorothea Salo and Jesse Hocking \\ University of Wisconsin-Madison Information School, US \\ Corresponding author: Dorothea Salo (salo@wisc.edu)
}

\begin{abstract}
Despite the short remaining time to rescue unique cultural and personal materials stored on many twentieth- and early twenty-first-century audiovisual and digital storage media, realistic rescue options are starkly limited. Building a rescue apparatus in house, especially to archival standards, requires significant expertise and expense and is often of limited continuing use. Outsourcing digital capture of these materials overwhelms the resources of even well-funded academic libraries and archives, never mind public libraries, small archives, and local historical societies. To address this problem realistically, the University of Wisconsin-Madison Information School has built and documented an in-house rescue installation called RADD (Recover Analog and Digital Data) as well as two self-contained, portable, and shippable rescue kits: PROUD (Portable Recovery of Unique Data) for digital materials and PRAVDA (Portably Reformat Audio and Video to Digital from Analog) for audio and video. All three units are actively rescuing cultural heritage materials, as well as serving training and outreach functions.
\end{abstract}

Keywords: audio digitization; video digitization; media archaeology

\section{Introduction}

In 2008, the University of Wisconsin School of Library and Information Studies (now the Information School) launched a Digital Curation course in the Master of Library and Information Studies program. The course's final project asked groups of students to tackle a real-world problem in research data management or digital preservation for a local client. Over years of hunting for suitable projects, one class of problem arose repeatedly: how to preserve the roomful of photographic slides, the file drawer of open-reel audiotapes or floppy diskettes, the closet full of VHS videotapes-audiovisual and digital storage media containing unique, irreplaceable content most at risk of partial or total information loss due to medium deterioration or equipment scarcity.

Rescuing such materials is financially and organizationally difficult for the following reasons:

- Remastering, even when equipment exists for the work, is usually a poor solution. Why remaster an open-reel audiotape to another open-reel audiotape, for example, when the most common and least evitable preservation problem with open-reel tapes is physical deterioration?

- Archival-quality equipment in working condition is often scarce, such that acquiring it is expensive or impossible, and the knowledge to keep equipment in good repair is disappearing.

- Some archival standards for digitization, especially for video, are unachievable with the hardware, software, and skills most readily available.

- Many, if not most, at-risk materials are in tiny collections-too small, scattered, and seemingly mundane to merit a digitization grant, much less in-house rescue apparatus.

- These collections often belong to individuals and small institutions possessing neither outsourcing money nor equipment and staff for in-house rescue.

Demanding archival-quality digital capture for these materials means dooming them; neither money, nor equipment, nor skilled staff will magically appear in time to save them. Completed suboptimal-quality 
capture, then, must be preferred to forever-deferred archival-quality capture for these materials. This logic underlies the construction of the rescue station Recover Analog and Digital Data (RADD) and the kits Portable Recovery of Unique Data (PROUD) and Portably Reformat Audio and Video to Digital from Analog (PRAVDA).

\section{Construction and Proof of Concept}

A 2014 group of Digital Curation students priced a 'good enough' audio/video reformatting and digital data rescue station, limiting themselves to equipment for materials held by the Information School and its faculty to keep project scope manageable. Course instructor Dorothea Salo then built RADD (see https://radd.dsalo. info/), acquiring some equipment from donations and other equipment with professional-development funds, and performed proof-of-concept work with materials from libraries and historical societies across Wisconsin. Among materials digitized at this stage were:

- A 1961 interview of Ho-Chunk elder John Davis by 11-year-old Peder Holmlund on a deteriorating openreel audiotape held by the Bangor and Area Historical Society.

- A series of oral histories with Pendarvis miners on open-reel audiotapes in varying conditions, held by the Mineral Point Library and Archives.

- A 1990s-era community roundtable on race from the Madison community television station WYOU on deteriorating VHS videotape.

- A 1970s West Bend High School band concert, recorded on vinyl in tribute to a graduated band member who died in Vietnam.

RADD can capture both audio and video to most acknowledged archival-quality standards, but its signaltesting and signal-improvement capacities are limited. Its digital data rescue capacity is roughly equal to that of a Forensic Recovery of Evidence Device (FRED) at about one-quarter of FRED's cost.

Unfortunately, RADD is immense and immovable, which makes teaching rescue skills to others and bringing rescue to materials (rather than risking shipment to Madison) difficult. Fortunately, in 2017 and 2018 the Institute for Museum and Library Services (IMLS) provided funding to pack as much of RADD's capacity as possible into the portable kits PROUD and PRAVDA.

PROUD matches RADD for digital data rescue except that PROUD does not have RADD's ability to handle drives requiring obsolete SCSI or parallel connectors. PRAVDA matches RADD for audio digitization, save that turntables, open-reel players, and 8-track players are too unwieldy to ship. (Should a player be available at a destination collection, however, it can be connected to PRAVDA.) Sadly, no reasonably priced archivalquality portable video-capture solution exists that works with a laptop. PRAVDA therefore uses a Roxio capture dongle that cannot capture lossless video, a suboptimal capture being better than no capture.

Since their construction, PROUD and PRAVDA have been terrific outreach and teaching tools, traveling to local Maker Faires, the Wisconsin Science Fest, several state library technology events, and the IMLSfunded Digital POWRR Institutes, which teach practical digital preservation to resource-strapped librarians and archivists. Cheered to hear that decent rescue rigs can be built economically, several Wisconsin public libraries and public-library consortia have started to build in-house or portable kits, which bodes well for Wisconsin's capacity to rescue at least some of its at-risk twentieth-century history.

\section{The Importance of Quality Documentation}

Information professionals often take for granted their familiarity with decades' worth of information carriers, from open-reel audiotapes to flash drives. However, data migration can be a daunting process to those unfamiliar with it. PROUD and PRAVDA rely on extensive documentation to be 'good enough' for untrained users lacking a trained professional nearby. Each kit contains written documentation and directions to video tutorials that explain how to unpack, set up, and operate the equipment (see https://radd.dsalo. info/2018/02/proud-and-pravda-draft-documentation-posted/ and the project's YouTube channel at https://www.youtube.com/channel/UCXx2hvOfSlpo7NSfF1cwlaw).

Documentation must be approachable, functional, and exhaustive. The PROUD and PRAVDA written documentation includes many screenshots to guide users through specific activities, which are taken from the computers in the kit so the interface is exactly the same as users see. Both written and video tutorials are customized for the exact equipment and software in the kits to eliminate confusion.

Build documentation for PROUD and PRAVDA (see https://radd.dsalo.info/2017/10/build-your-ownrescue-kit/) went moderately viral on Twitter and has been downloaded several hundred times since its October 2017 release. 


\section{Future Work}

RADD, PROUD, and PRAVDA point to several areas for future work:

- State and regional dissemination networks for kits, which might operate through the Digital Public Library of America service-hub network, library consortia, or state libraries/archives.

- National or even global inventories of A/V digitization and digital data rescue equipment and expertise.

- A workable sustainability and logistics model for shipping kits where needed.

\section{Acknowledgements}

The authors gratefully acknowledge the Ira and Ineva Reilly Baldwin Wisconsin Idea Endowment and the Institute for Museum and Library Services (grant number SP-02-16-0015-16) for supporting RADD, PROUD, and PRAVDA.

\section{Competing Interests}

The authors have no competing interests to declare.

How to cite this article: Salo, Dorothea and Jesse Hocking. 2018. Digital Reformatting and Data Rescue with RADD and the PROUD and PRAVDA Kits. KULA: Knowledge creation, dissemination, and preservation studies 2(1): 14 DOI: https://doi.org/10.5334/kula.19

Submitted: 02 February $2018 \quad$ Accepted: 08 May 2018 Published: 29 November 2018

Copyright: ( $) 2018$ The Author(s). This is an open-access article distributed under the terms of the Creative Commons Attribution 4.0 International License (CC-BY 4.0), which permits unrestricted use, distribution, and reproduction in any medium, provided the original author and source are credited. See http://creativecommons.org/ licenses/by/4.0\%. 